\title{
Prostate cancer susceptibility gene HIST1H1A is a Research Paper of androgen receptor signaling and epithelial to mesenchymal transition
}

\author{
Kendra A. Williams ${ }^{1}$, Minnkyong Lee ${ }^{1}$, Jean M. Winter ${ }^{1}$, Derek E. Gildea ${ }^{2}$, Carla \\ Calagua $^{3}$, Natasha L. Curry ${ }^{1}$, Jens Lichtenberg ${ }^{1}$, Huihui Ye $^{3}$ and Nigel P.S. Crawford ${ }^{1,4}$ \\ ${ }^{1}$ Genetics and Molecular Biology Branch, National Human Genome Research Institute, National Institutes of Health, Bethesda, \\ Maryland, USA \\ ${ }^{2}$ Computational and Statistical Genomics Branch, National Human Genome Research Institute, National Institutes of Health, \\ Bethesda, Maryland, USA \\ ${ }^{3}$ Department of Pathology, Beth Israel Deaconess Medical Center, Harvard Medical School, Boston, Massachusetts, USA \\ ${ }^{4}$ Current address: Sanofi, Bridgewater, New Jersey, USA
}

Correspondence to: Nigel P.S. Crawford, email: nigel.crawford@sanofi.com

Keywords: ATAC-seq; HISTIHIA; neuroendocrine prostate cancer; epithelial mesenchymal transition; Wnt pathway

Received: October 26, $2017 \quad$ Accepted:May 01, $2018 \quad$ Published: June 19, 2018

Copyright: Williams et al. This is an open-access article distributed under the terms of the Creative Commons Attribution License 3.0 (CC BY 3.0), which permits unrestricted use, distribution, and reproduction in any medium, provided the original author and source are credited.

\section{ABSTRACT}

In 2018, approximately 165,000 new prostate cancer (PC) cases will be diagnosed, and over 29,000 men will succumb to PC in the U.S. alone. The means of assessing outcome in the clinic are inaccurate, and there is a pressing need to more precisely identify men at risk of aggressive PC. We previously identified HIST1H1A as a susceptibility gene for aggressive PC. HIST1H1A encodes H1.1, a member of the linker histone family that is involved in chromatin organization and compaction. To understand the molecular basis of aggressive PC, we have characterized how germline variation modulates susceptibility to neuroendocrine differentiation, which is a form of aggressive PC. Immunohistochemistry studies revealed that HIST1H1A is over-expressed in normal human prostate tissue compared to prostate adenocarcinoma. Functional characterization of HIST1H1A in prostate LNCaP cells indicated that HIST1HA over-expression increased cell growth, as well as the expression of neuroendocrine and epithelial-to-mesenchymal markers in vitro. Assay for Transposase-Accessible Chromatin (ATAC-seq), which is used to assess chromatin compaction and thus the transcriptional availability of individual genomic regions, demonstrated that $\mathrm{H1.1}$ plays a prominent role in modulating Wnt signaling pathway genes, which are implicated in prostate tumorigenesis. These results demonstrate that HIST1H1A is a modulator of aggressive PC susceptibility.

\section{INTRODUCTION}

Prostate cancer (PC) is one of the most commonly diagnosed male cancers in the U.S. It is estimated that approximately 165,000 new PC cases will be diagnosed, and over 29,000 men will die from this disease in 2018 [1]. Measurement of serum prostate specific antigen (PSA) is the established screening tool used for detecting PC. However, there remain legitimate questions regarding the accuracy of this test, since it has no predictive prognostic value at diagnosis which leads to high rates of overdiagnosis and over-treatment [2-4]. Therefore, more indepth understanding of the mechanisms involved in PC progression is needed to accurately identify men at risk for developing a more aggressive and fatal form of this disease, and to prevent over treatment of men with low risk disease.

Survival and growth of malignant PC cells are dependent on the androgen receptor (AR) signaling pathway. Therefore, androgen deprivation therapy (ADT) with 
therapeutic agents such as abiraterone and enzalutamide is the first line of treatment for patients suffering from locally advanced PC [3,5-10]. Many patients exhibit an initial therapeutic response to ADT; however, long term treatment with ADT results in progression to an aggressive, metastatic, and ultimately fatal disease form $[11,12]$. Interestingly, autopsy studies have demonstrated that at least $25 \%$ of castrate resistant tumors harbor neuroendocrine (NE) histological characteristics, indicating that the incidence of NE prostate cancer (NEPC) is much more common than previously thought $[13,14]$. With the widespread use of ADT for treating PC, the incidence of patients with NEPC is expected to rise. Therefore, identifying novel molecular targets, and understanding the mechanisms driving NEPC is of critical importance.

Hereditary variation can contribute considerably to an individual's risk for developing aggressive and metastatic PC [15-17]. Our earlier study identified aggressive PC susceptibility genes using the C57BL/6$\mathrm{Tg}$ (TRAMP) $8247 \mathrm{Ng} / \mathrm{J}$ (TRAMP) mouse model of NEPC. Quantitative trait locus (QTL) mapping in transgenepositive (TRAMP $\times$ NOD/ShiLtJ) F2 intercross males, and expression QTL mapping using primary tumor microarray data identified 35 aggressive PC candidate genes that harbored variants associated with aggressive disease characteristics. Analysis of QTL data demonstrated that differential expression of Hist1hla in prostate tumor samples, as a consequence of germline variation, influences disease aggressiveness in this mouse model. In silico analysis identified HISTIHIA as having an expression level associated with patient outcome in a human PC gene expression dataset and harboring a single nucleotide polymorphism associated with lymph node metastasis in the PC genome wide association study (GWAS) [15].

The linker histone family member H1.1 forms an integral part of nucleosome, which are the fundamental unit of eukaryotic chromatin. Linker histones interact with both DNA and the core histone octamer to form a unique structural motif that allows for correct folding and compaction of chromatin [18]. Linker histone proteins have several important functions in the nucleosomes. These functions include positioning and spacing within the nucleus, nucleosome stabilization via chromatin compaction, and controlling gene expression by preventing access of transcription factors and RNA polymerase to the DNA [19]. The H1 linker histone family consists of seven somatic variants H1FO, HISTIH1A (H1.1), HIST1HIC (H1.2), HIST1HID (H1.3), HIST1H1E (H1.4), HISTIH1B (H1.5), and HIFX [18]. Interestingly, while the replication-dependent somatic histones $\mathrm{H} 1.2-\mathrm{H} 1.5$ are found depleted in active promoter regions and enriched in areas associated with repression, H1.1 is found enriched in the promoter regions and is associated with transcriptional activity [20]. Additionally, mouse Histlhla is highly expressed in organs with an abundance of proliferating cells, such as the thymus, spleen, and testis [21].
In vitro analyses in our study have relied on two cell lines: LNCaP and PC-3. LNCaP is an AR-positive cell line that is reminiscent of prostate adenocarcinoma. Conversely, PC-3 is an AR-negative cell line that actively expresses NE markers [22] and is thus more comparable to NE prostate carcinoma. In this study, we show for the first time that H1.1 expression is significantly higher in normal human prostate tissue compared to prostate adenocarcinoma. In addition, ectopic expression of HIST1H1A suppressed cell growth, invasion and migration in vitro in PC-3 cells. Microarray analysis using $\mathrm{LNCaP}$ cells indicated that HISTIHIA over-expression promotes either an increase or decrease in over 1,900 transcripts. Ingenuity Pathway Analysis (IPA) suggested that both AR signaling and epithelial-to-mesenchymal transition (EMT) pathways are affected in an HISTIHIA dependent manner. In line with this finding, protein and differential gene expression data demonstrated that HISTIH1A over-expression decreases $\mathrm{AR}$ levels and increases EMT markers in an AR positive environment. Assay for Transposase-Accessible Chromatin (ATAC)-sequencing analysis suggested that over-expression of H1.1 impacts the genome landscape in PC cells. Validation of ATACseq data using Chromatin Immunoprecipitation and qPCR (ChIP-qPCR), demonstrated that H1.1 occupancy influences important pathways related to aggressive tumorigenesis such as WNT pathway, AR signaling, and EMT. This study is the first to demonstrate a functional role for HIST1H1A in influencing aggressive PC susceptibility.

\section{RESULTS}

\section{HIST1 gene members are associated with aggressive prostate cancer}

A systems genetics approach in (TRAMP x NOD/ ShiLtJ) F2 intercross males was previously used to identify 35 aggressive PC modifier genes. Of these genes, six Hist 1 family members were identified as being associated with susceptibility to aggressive PC (Hist1hla, Hist1h2ab, Hist1h3c, Hist1h3e, Hist1h4a, and Hist1h4h) [15]. In this study, further analysis determined that the peak regions of linkage of two loci on mouse Chr. 13 associated with primary tumor burden and nodal metastasis burden were in proximity to the mouse Histl locus. This is of interest since an earlier family-based linkage study demonstrated that the syntenic region of the human genome encompassing the HIST1 locus (Chr. 6p22.3) is a risk locus for aggressive PC [23]. Given the prominence of Hist1 locus genes in the list of 35 aggressive PC susceptibility candidate genes in (TRAMP $\times$ NOD/ShiLtJ) F2 males, we analyzed the relationship between expression levels of the human orthologs of the six Hist 1 genes and aggressive PC. An in silico validation using logistic regression (LR) analysis to determine the correlation between the expression level 
of all six HIST1 genes and aggressive PC clinical variables was performed using human PC gene expression datasets. LR analysis was performed using three different cohorts: the Cancer Genome Atlas [TCGA] prostate adenocarcinoma [PRAD] $(n=497)$ [24]; GSE21032 $(n=150)$ [24]; and GSE49961 $(n=545)$ [25] which consist of microarray datasets. These analyses indicated that of the six HIST1 genes identified in (TRAMP $\times$ NOD/ShiLtJ) F2 intercross males, the expression levels of HISTIH1A and HIST1H4H were associated with aggressive $\mathrm{PC}$ clinical variables. In the GSE21032 cohort, HIST1H1A expression was associated with Gleason Score (odds ratio $=0.39 ; 95 \% \mathrm{CI}=0.22$ $\left.0.67 ; P=8.00 \times 10^{-4} ; \mathrm{FDR}=0.03\right)$. In the TCGA cohort, HIST1H4H expression was associated with nodal stage (odds ratio $=1.63 ; 95 \% \mathrm{CI}=1.26-2.11 ; P=2.00 \times 10^{-4}$; FDR $=0.01$ ). Additional results for all six HIST1 genes are shown in Supplementary Table 1. To further examine the association of HIST1H1A and HIST1H4H expression with survival, we performed Kaplan-Meier survival analysis. The analyses revealed that subjects exhibiting differential expression of either of these genes in primary tumors in the GSE46691 cohort exhibited an improved overall survival and a lower risk of disease recurrence. Specifically, the expression of HIST1H1A and HIST1H4H were significantly altered in $9.9 \%(54 / 545)$ of the cases (Figure 1A and Supplementary Table 2). Both overall survival (Figure 1B) and disease recurrence (Figure 1C) were significantly improved in patients with higher than average gene expression of HISTIH1A and lower than average gene expression of $\mathrm{HIST} 1 \mathrm{H} 4 \mathrm{H}$ in primary tumors compared to patients with apparently normal levels of these two genes (log-rank $P=0.020$ and 0.039 respectively), indicating that higher than average gene expression of HIST1H1A and lower than average gene expression of $H I S T 1 H 4 H$ were associated with a lower likelihood of aggressive disease. No association between HISTIHIA and HIST1H4H expression and survival was observed in the GSE21032 and TCGA cohorts (data not shown).

\section{Characterization of HISTIHIA in prostate tissue microarray reveals higher expression in prostate normal tissue compared to prostate adenocarcinoma}

To investigate the clinical relevance of changes in $\mathrm{H} 1.1$ expression in $\mathrm{PC}$, we performed immunohistochemistry (IHC) staining using prostate tissue microarray (TMA). TMAs, which were obtained from The Prostate Cancer Biorepository Network, consisted of 80 cases of normal prostate epithelial and matched adenocarcinoma samples. Clinical characteristics of patient samples can be found in Supplementary Table 3. Strong H1.1 staining was observed in normal prostate epithelium (Figure 2A and 2B) compared to weaker staining in the prostate adenocarcinoma (Figure 2C and 2D). Significantly higher immunoscores (intensity of positive staining $\times$ percentage of positive cells) of H1.1 staining was observed in normal prostate epithelial tissue $\left(P<1.0 \times 10^{-4}\right.$; Figure 2E) as well as stromal tissue $\left(P=7.0 \times 10^{-4}\right.$; Figure $2 \mathrm{~F}$ ) compared to adenocarcinoma tissue.

\section{HIST1H1A suppresses growth and metastasis in the androgen receptor negative $\mathrm{PC}-3$ cells}

To better understand the role HIST1H1A plays in PC aggressiveness, we stably over- expressed HIST1H1A in the aggressive AR-negative human PC cell line PC-3 using lentiviral transduction. Control cells were generated by transducing PC-3 cells with lentivirus containing an empty vector. HIST1H1A expression was confirmed using RT-qPCR and Western blot (Supplementary Figure 1A and $1 \mathrm{~B})$. To determine how in vitro growth rates were affected in cells expressing HIST1H1A versus control, we performed growth curve analysis. Over-expression of HIST1H1A significantly suppressed cell growth on day six compared to control, $P=2.08 \times 10^{-8}$ (Figure 3A). To explore HIST1H1A involvement in cell migration and invasion, we employed a trans-well migration system, which allow movement of cells across a membrane coated with collagen IV or Matrigel, respectively. Overexpression of HIST1H1A significantly suppressed migration (average absorbance $560 \mathrm{~nm}=0.25 \pm 0.05$ ) versus control (average absorbance $560 \mathrm{~nm}=0.35 \pm 0.08$, $P=0.002$ ), and invasion (average absorbance $560 \mathrm{~nm}=$ $0.20 \pm 0.02$ ) versus control (average absorbance $560 \mathrm{~nm}=$ $0.23 \pm 0.05, P=0.04$; Figure $3 \mathrm{~B}$ and $3 \mathrm{C}$ ).

Subsequently, we examined the effect of HIST1H1A over-expression on tumor growth and dissemination in vivo. We investigated the ability of HIST1H1A to modulate tumor growth in a xenograft flank assay by injecting control cells, or cells over-expressing HIST1H1A into the flanks of $\mathrm{NU} / \mathrm{J}$ mice and observed tumor growth over a five-week period. HIST1H1A significantly suppressed tumor volume compared to the control group (average tumor volume $=$ $212 \pm 133 \mathrm{~mm}^{3}$ versus $1,305 \pm 896 \mathrm{~mm}^{3}, P=6.79 \times 10^{-5}$; Figure 3D). To evaluate the effect of HIST1H1A on tumor dissemination in vivo, we performed intra-cardiac injections in NU/J mice using PC-3 cells tagged with luciferase (PC3 Luc), and over-expressing either HIST1H1A or control vector. Tumor dissemination was determined by quantifying bioluminescent signals of cells over-expressing either HIST1H1A or control vector over six weeks. A significant reduction in dissemination of $\mathrm{PC}-3$ cells was observed in the HIST1H1A group compared to the control group (average flux $9.17 \times 10^{4} \pm 2.34 \times 10^{5}$ versus $1.38 \times 10^{6} \pm 1.12 \times 10^{6}$, $P=0.001$; Figure $3 \mathrm{E}$ ).

\section{HISTIH1A increases the aggressiveness of the androgen receptor-positive human prostate cancer $\mathbf{L N C a P}$ cell line}

To characterize the functional role HIST1H1A plays in an androgen receptor positive environment, we used lentiviral transduction techniques to stably over-express 
HIST1H1A or a control vector in the LNCaP PC cell line as was previously performed in PC-3 cells. Growth curve analysis revealed that cells over-expressing $H I S T 1 H 1 A$ exhibited a significant increase in cell growth compared to the control group $\left(P=7.45 \times 10^{-15}\right.$; Figure 4A). We next performed soft agar assay to determine the effect of HIST1H1A over-expression on cell growth in 3D culture.
Over-expression of HIST1H1A significantly enhanced the number of colonies found growing in suspension compared to the control group ( $468 \pm 87.5$ versus $247 \pm 96$ colonies, $P=0.014$; Figure 4B). To investigate the in vitro migratory and invasive potential of cells expressing HIST1H1A in an AR-positive environment, we performed transwell assays. LNCaP cell migration was not significantly
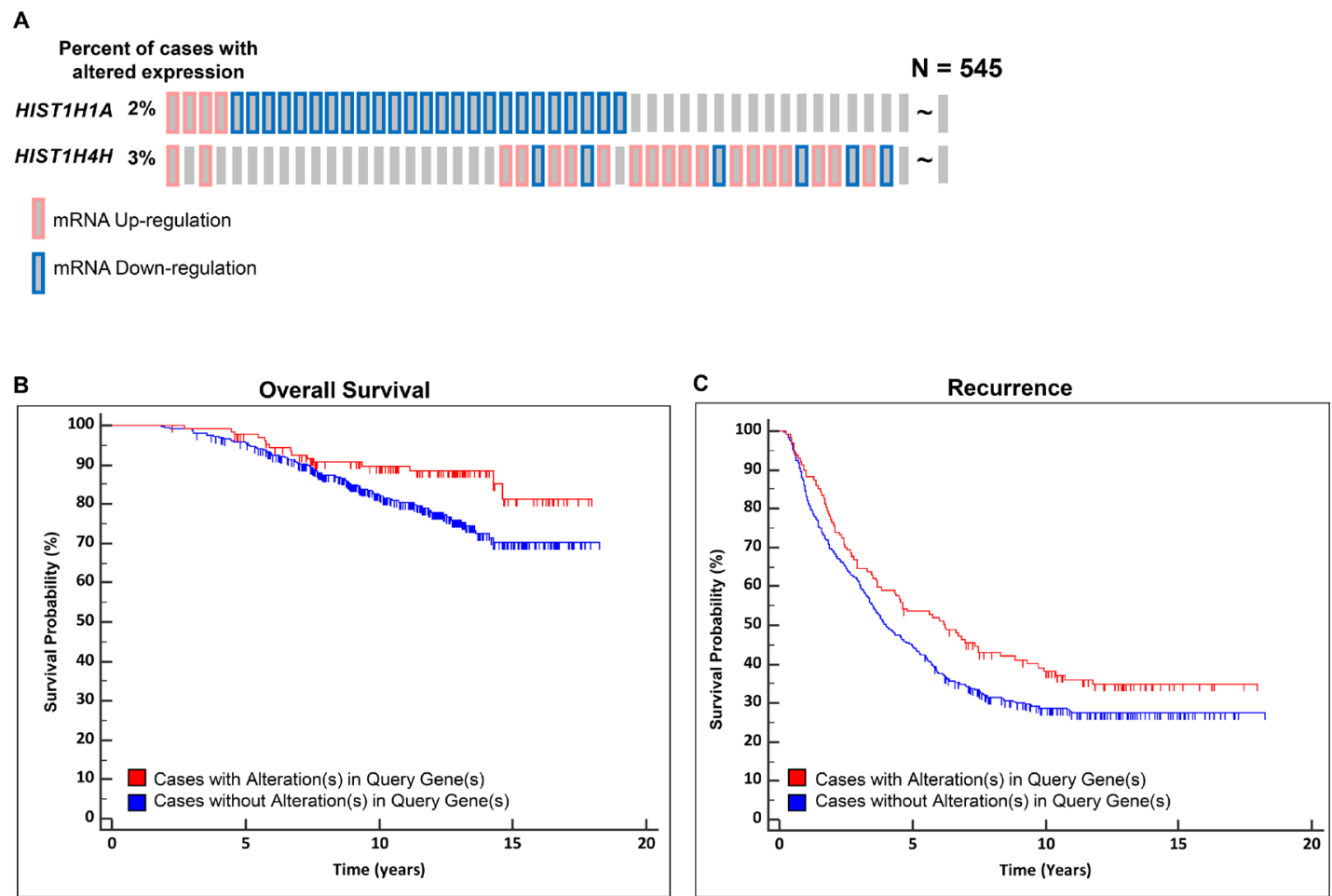

Figure 1: Expression levels of two HIST1 genes are associated with aggressive prostate cancer outcomes. Oncoprint gene expression analysis illustrates the percentage of patients harboring aberrant expression levels of HIST1H1A and HIST1H4H (A). Patients with altered expression of HIST1H1A and HIST1H4H are associated with better overall survival, $\log$ rank $P=0.020(\mathbf{B})$ and reduced disease recurrence, $\log \operatorname{rank} P=0.039(\mathbf{C})$.

A

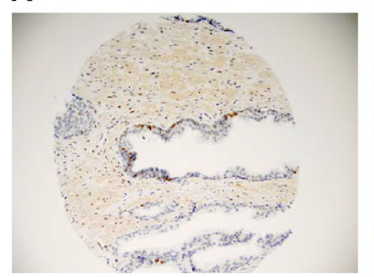

C

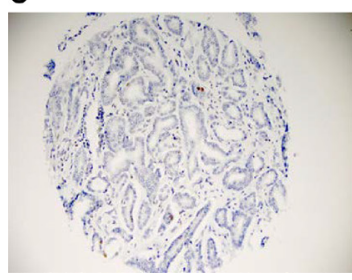

B

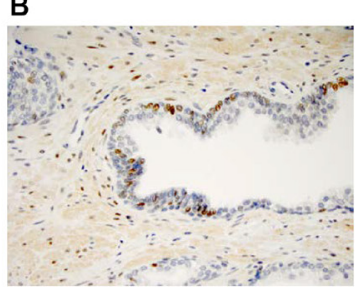

D

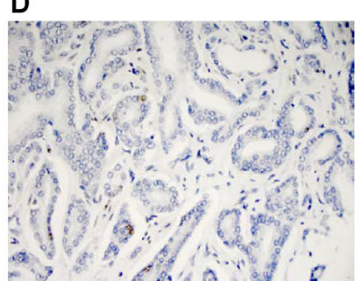

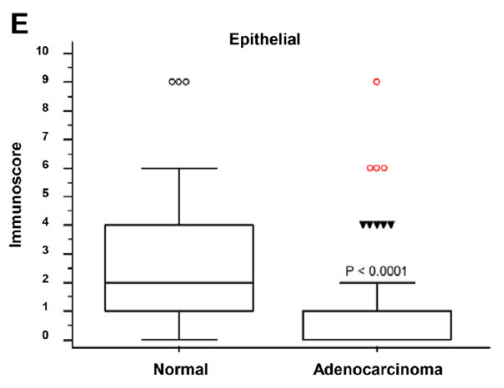

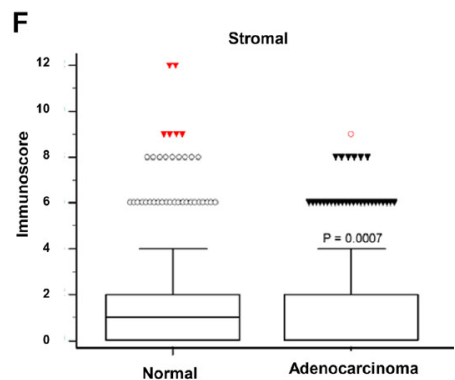

Figure 2: HIST1H1A expression is down-regulated in prostate adenocarcinoma. Representative images of histological sections showing positive staining of H1.1 in normal prostate at $20 \times$ and $40 \times($ A and B), and prostate adenocarcinoma at $20 \times$ and $40 \times$ $\left(\mathbf{C}\right.$ and D). Box plots representing immunoscore (immunointensity $\times$ percentage score) in prostate epithelial tissue, $P=1.0 \times 10^{-4}(\mathbf{E})$, and prostate stromal tissue, $P=7.0 \times 10^{-4}(\mathbf{F})$. $P$-values were determined using Wilcoxon rank sum test $(n=80$ cases vs. $n=80$ control $)$. 
impacted by HIST1H1A over-expression (Figure 4C). However, invasion was significantly decreased with the over-expression of HIST1H1A compared to the control group (average absorbance $560 \mathrm{~nm}=0.030 \pm 0.009$ ) versus (average absorbance $560 \mathrm{~nm}=0.060 \pm 0.020$; $P=6.22 \times 10^{-4}$; Figure 4D). Table 1 presents a summary of in vitro and in vivo studies performed in $\mathrm{PC}-3$ and LNCaP cells over-expressing HIST1H1A relative to cells expressing the control vector.

\section{Over-expression of HIST1H1A impacts global gene expression in prostate cancer cell lines}

To gain insight into the mechanism underlying the influence of HIST1H1A in promoting a more aggressive $\mathrm{PC}$ phenotype in $\mathrm{LNCaP}$ cells, we used microarray analysis to evaluate the expression profile of clonal isolates expressing either HISTIHIA or control vector. Over 1,900 transcripts were found to be significantly dysregulated in response to HIST1H1A over-expression (fold change $> \pm 2$; false discovery rate [FDR] $<0.050$; Figure 4E, Supplementary Table 4). IPA identified several canonical signaling pathways and molecules affected by HIST1H1A over-expression, including PTEN signaling $\left(\mathrm{FDR}=1.55 \times 10^{-4}\right)$, regulation of EMT $(\mathrm{FDR}=3.98 \times$ $\left.10^{-4}\right)$, and the $\mathrm{WNT} / \mathrm{Ca}^{+}$pathway $\left(\mathrm{FDR}=8.51 \times 10^{-4}\right)$ (Supplementary Tables 5 and 6).

Since HIST1H1A over-expression affected several factors of the EMT signaling pathway, we sought to validate several genes found in the EMT pathway by performing qRT-PCR. Our analyses confirmed that HIST1H1A over-expression in LNCaP cells significantly affected several prominent EMT markers. Gene expression for mesenchymal marker Vimentin (VIM), and transcription factors Slug (SNAI2), Zinc finger E-box binding homeobox $(Z E B) 1$ and 2 were significantly upregulated; $V I M$ (fold change $=34.32 \pm 2.63, P=4.29 \times 10^{-6}$ ), SNAI2 (fold change $=63.91 \pm 11.61, P=2.63 \times 10^{-4}$ ),
A

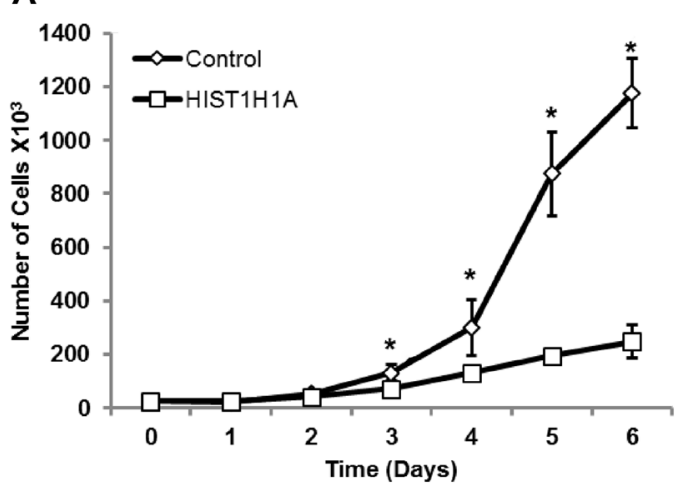

D

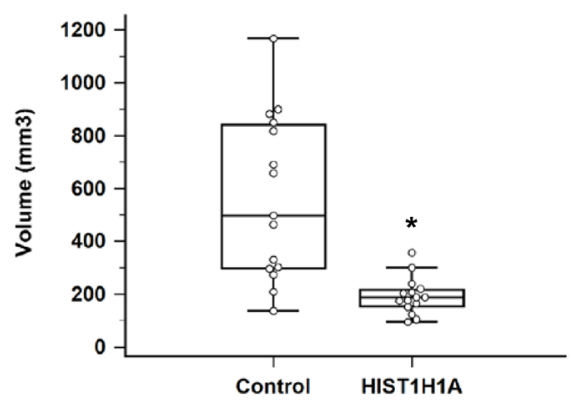

B

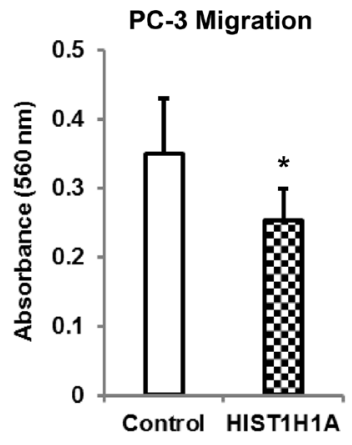

C

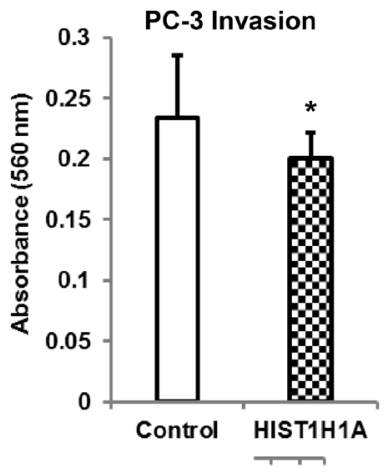

E

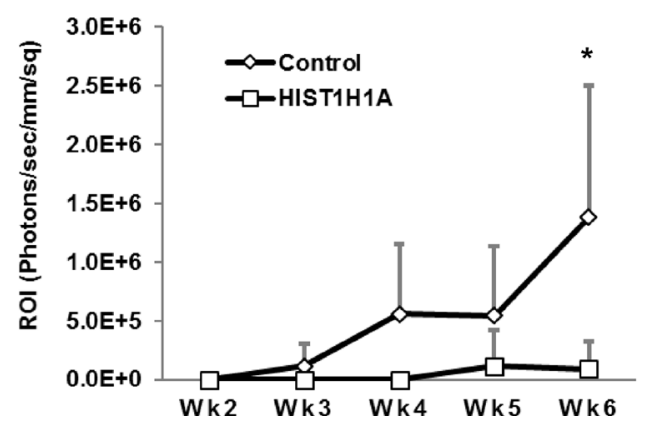

Figure 3: HIST1H1A inhibits cell growth, migration, and invasion both in vitro and in vivo in androgen receptor negative PC-3 cells. Growth was monitored in three clonal isolates of PC-3 cells over-expressing HISTIH1A or control vector, $P\left({ }^{*}\right)<0.01$ (A). In vitro cell migration was determined in PC-3 cells over-expressing HIST1H1A or control vector by monitoring migration of cells across trans-well membrane coated with collagen, $P\left({ }^{*}\right)=0.002(\mathbf{B})$. In vitro cell invasion was determined in PC-3 cell overexpressing HIST1H1A or control vector by monitoring the ability of cells to invade a Matrigel matrix, $P\left({ }^{*}\right)=0.042(\mathbf{C})$. Cells expressing HIST1H1A or control vector were injected into the flanks of NU/J mice, and tumor size was measured once a week for 5 weeks using a digital caliper. Results are expressed as tumor volume, Volume $=\left(\right.$ Width $^{2} \times$ Length $) / 2,(n=15), P\left({ }^{*}\right)=6.79 \times 10^{-5}($ D $)$. PC-3 Luc cells over-expressing HIST1H1A or control vector and co-expressing the luciferase gene were injected into the left ventricle of NU/J male mice. Bioluminescence was quantified by imaging mice weekly using an IVIS Xenogen chamber to monitor dissemination of cancer cells, which is measured by photon flux $(\mathrm{P} / \mathrm{sec} / \mathrm{mm} / \mathrm{sq})(n=12), P\left({ }^{*}\right)=0.001(\mathbf{E})$. Results are presented as mean + SD of at least two experiments, statistical significance was calculated using the Student's $T$-test, or ANOVA with $P\left({ }^{*}\right)<0.05$ representing statistical significance between HIST1H1A and control vector group. 
$Z E B 1$ (fold change $=2.07 \times 10^{3} \pm 4.47 \times 10^{2}, P=4.93$ $\times 10^{-4}$ ) and $Z E B 2$ (fold change $=4.23 \times 10^{3} \pm 9.90 \times 10^{2}$, $\left.P=6.74 \times 10^{-4}\right)$. However, gene expression for epithelial markers Keratin 18 (KRT18), Tight junction protein 1 (TJP1) and E-cadherin (CDH1) were significantly suppressed; KRT18 (fold change $=1.60 \times 10^{-1} \pm 2.91 \times 10^{-2}$, $P=0.001), T J P 1$ (fold change $=2.5 \times 10^{-1} \pm 4.37 \times 10^{-2}, P$ $=0.01)$, and $C D H 1$ (fold change $=5.55 \times 10^{-4} \pm 4.97 \times 10^{-4}$, $P=5.72 \times 10^{-5}$; Figure $\left.4 \mathrm{~F}\right)$. Western blot analysis confirmed that over-expression of HIST1H1A affects the protein expression of several of these EMT molecules. In particular, loss of protein expression of epithelial marker E-cadherin in the presence of HIST1H1A, was associated with increase protein expression of Vimentin (Figure 4G, Supplementary Figure 2). Taken together, these data suggest that HIST1H1A promotes aggressive PC development. Furthermore, aggressive PC development occurs simultaneously with aberrant changes in EMT factors at the gene and protein level.

Among the list of dysregulated transcripts identified in LNCaP cells using microarray analysis, there were several NE genes that are associated with aggressive PC (Table 2, Supplementary Table 4). This is of interest given that Histlhla was identified as an aggressive disease modifier using the TRAMP mouse model of NEPC [15]. To validate the microarray results, we performed qRTPCR analysis, which confirmed that over-expression of HIST1H1A significantly enhanced gene expression of Synaptophysin $(S Y N)$ (fold change $=4.64 \pm 0.66, P=$ $\left.3.55 \times 10^{-6}\right)$, Neural Cell Adhesion Molecule 1 (NCAM1) $\left(\right.$ fold change $\left.=1.06 \times 10^{3} \pm 1.47 \times 10^{2}, P=22.02 \times 10^{-5}\right)$, Chromogranin $B(C H G B)$ (fold change $=6.7 \pm 1.46$, $\left.P=3.91 \times 10^{-5}\right)$, and Ubiquitin Conjugating Enzyme E2 $C(U B E 2 C)$ (fold change $=1.70 \pm 0.45, P=0.04)$, but significantly suppressed $A R$ (fold change $=3.78 \times 10^{-4}$ $\left.\pm 1.29 \times 10^{-4}, P=1.99 \times 10^{-4}\right)$ and Kallikrein-Related Pepidase $3(K L K 3)$ (fold change $=3.73 \times 10^{-6} \pm 5.77 \times$ $10^{-6}, P=0.03$ ) (Figure 4H). Conversely, over-expression of HIST1H1A in the aggressive PC-3 cell line had an opposite effect on NE markers. Specifically, qRT-PCR analysis demonstrated that HIST1H1A over-expression in PC-3 cells significantly suppressed the expression of $S Y N$ $\left(\right.$ fold change $\left.=8.00 \times 10^{-2} \pm 0.03, P=0.008\right), N C A M 1$ $\left(\right.$ fold change $=5.51 \times 10^{-5} \pm 5.13 \times 10^{-5}, P=4.03 \times 10^{-6}$ ) and $C H G B$ (fold change $=2.56 \times 10^{-2} \pm 7.67 \times 10^{-3}$, $P=0.04$; Figure 4I) compared to the control group.

\section{ATAC-seq analysis identified enhanced open chromatin regions in LNCaP cells over- expressing HISTIH1A}

To investigate how HIST1H1A influences chromatin compaction, we used ATAC-seq, which is based on the integration of $\mathrm{Tn} 5$ transposase in the open chromatin region [26]. Three LNCaP cell clonal isolates stably overexpressing either HISTIH1A or control vector were used to generate sequencing libraries. Figure $5 \mathrm{~A}$ represent regions of both increased and decreased chromatin compaction in HIST1H1A versus the control group, as reflected by varying degrees of peak regions. ATAC-seq analysis indicated that over-expression of HIST1H1A increased the number of open chromatin regions to 19,277 compared with 16,173 in control cells. There was a significant overlap of genes harboring open chromatin regions, with 10,219 (74\%) of these genes demonstrating overlap between HIST1H1A and control group (Figure 5B). However, there were also unique subsets of genes that lost open chromatin regions $(1,064 ; 7.6 \%)$, and gained open chromatin regions $(2,583$; $18.6 \%$ ) with over-expression of HIST1H1A (Figure 5B). A complete list of genes identified in the HIST1H1A and control groups can be found in Supplementary Tables 7 and 8 respectively. To determine the pathways affected by these changes in chromatin landscape attributed to HIST1H1A over-expression, IPA was performed using the list of genes identified as unique to either the HISTIHIA or control group. Three distinct clusters were identified based on their functional characteristics (Supplementary Tables 9-11). Two lists were associated with LNCaP cells over-expressing HIST1H1A, one which consist of WNT3a target molecules, and the second consist of WNT signaling molecules. The third list include molecules involve in androgen biosynthesis and was associated with $\mathrm{LNCaP}$ cells over-expressing the control vector.

To confirm that HIST1H1A is involved in regulating the expression of WNT pathway target genes, we performed ChIP-qPCR to investigate proteinDNA interactions at specific genomic sites identified from the ATAC-seq analysis. Fragments of cross-linked chromatin of hemagglutinin (HA)-tagged HIST1H1A were immunoprecipitated from three LNCaP cell clonal isolates over-expressing HIST1H1A or control vector using an HA antibody. Quantitative-PCR was performed using several sets of primers targeting molecules involved in both the canonical and non-canonical WNT pathways. Immunoglobulin $\mathrm{G}(\mathrm{IgG})$ was used as a negative control. In samples over expressing $H I S T 1 H 1 A$, signals were enriched for $W N T 3 A$, SERPINB, WNT5A, DKK1, DKK2, DVL2, SOX9, TGF $1, T I M P 3$, and $C D H 2$ compared to control group, $P\left({ }^{*}\right)<0.05$ (Figure $5 \mathrm{C}$ ). These data suggest that in an AR-positive environment, HIST1H1A may be involved in promoting a NE phenotype by influencing members of the WNT pathway.

\section{DISCUSSION}

In this study, we explored the functional role HIST1H1A plays in the development of aggressive PC. We hypothesized that HIST1H1A modulates chromatin structure, which in turn influences the expression of genes and pathways critical to the development of aggressive PC.

An earlier study demonstrated that mice lacking Histlhla exhibit normal development [27]. While the 
functional role of HIST1H1A in PC has not been previously investigated, there are some studies investigating the expression of HISTIH1A and other linker histones genes in different cancer types. The expression of HIST1H1A along with HIST1HIE, HIF0, and HIFX were significantly reduced in ovarian malignant adenocarcinoma compared to benign tumor, while the linker histone HIST1H1D showed the reverse trend [28]. In addition, hierarchical clustering of gene expression patterns further indicate that these four linker histones can discriminate between ovarian adenomas and adenocarcinoma, suggesting their potential as biomarkers for aggressive disease [28]. In an immunohistochemistry study, HIST1H1B was shown to be positively correlated with tumor grade, in that its nuclear expression increased with the grade of pulmonary NE carcinomas [29]. HIST1H1B protein expression was also assessed in human prostate adenocarcinoma, which revealed strong nuclear reactivity in most prostate adenocarcinoma cases compared
A
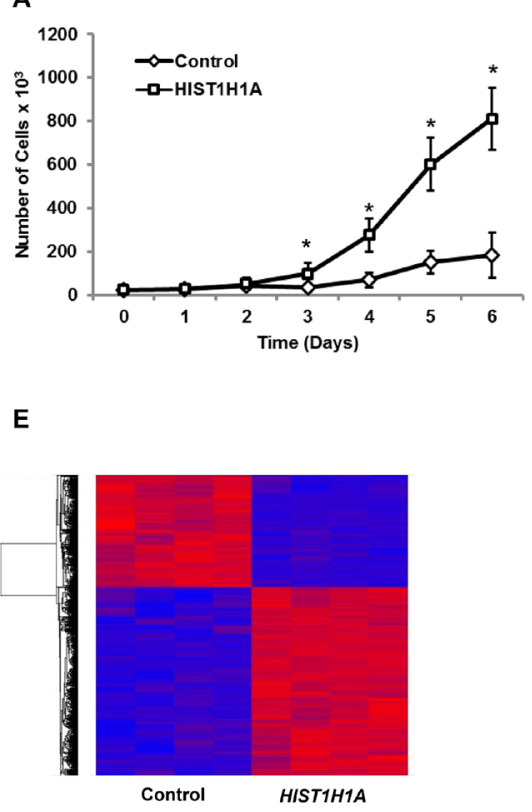

B

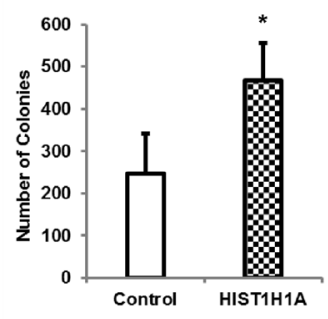

C

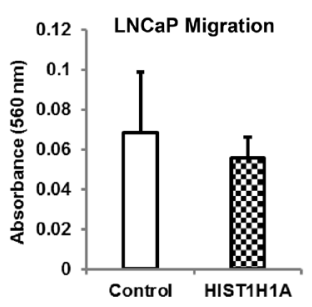

D

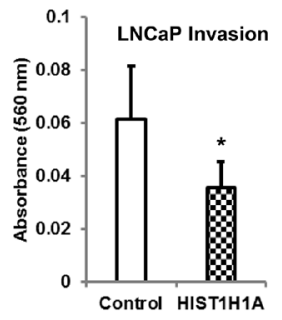

G
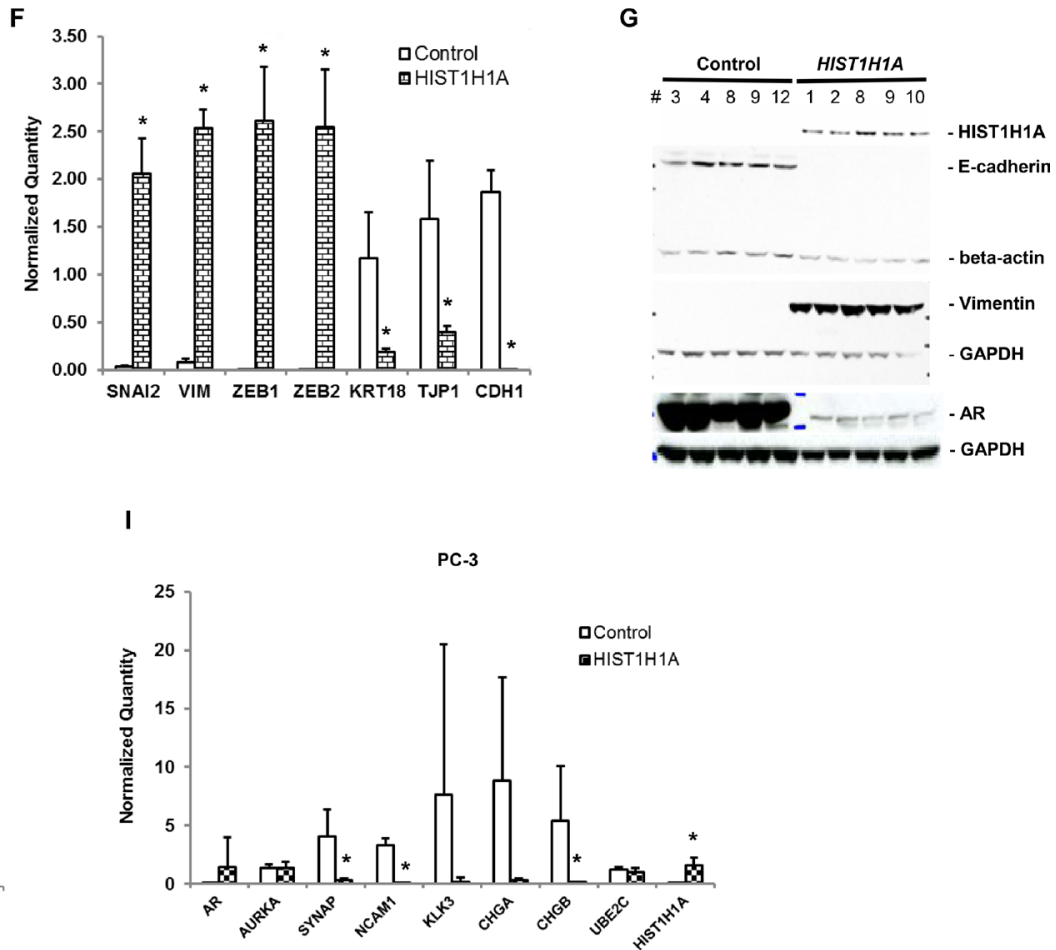

Figure 4: HISTIH1A enhanced the expression of neuroendocrine and epithelial-to-mesenchymal markers in the androgen receptor-positive LNCaP human prostate tumor cells. Growth was monitored in three clonal isolates of LNCaP cells over-expressing HIST1H1A or control vector, $P\left({ }^{*}\right)<0.001$ (A). Growth in suspension was monitored in LNCaP cells over-expressing HIST1H1A or control vector by growing cells in soft agar, $P\left({ }^{*}\right)=0.014(\mathbf{B})$. In vitro cell migration was determined in LNCaP cells overexpressing HIST1H1A or control vector by monitoring migration of cells across trans-well membrane coated with collagen, $P=$ n.s. $(\mathbf{C})$. In vitro cell invasion was determined in LNCaP cells over-expressing HIST1H1A or control vector by monitoring the ability of cells to invade a Matrigel matrix, $P\left({ }^{*}\right)=6.22 \times 10^{-4}(\mathbf{D})$. Global gene expression was quantified in LNCaP cells over-expressing HIST1H1A or control vector using microarray analysis. Heat map represents relative gene expression of four clonal isolates over-expressing HIST1H1A or control vector $(\mathbf{E})$. qRT-PCR was used to quantify gene expression of EMT markers in four clonal isolates of LNCaP cells over-expressing HIST1H1A or control vector, $P\left({ }^{*}\right)<0.05(\mathbf{F})$. Western blot was used to quantify protein expression of EMT markers in LNCaP cells overexpressing HIST1H1A or control vector, GAPDH served as a loading control (G). qRT-PCR was used to quantify gene expression of NE markers in four clonal isolates of LNCaP cells, $P\left(^{*}\right)<0.05(\mathbf{H})$ and PC-3 cells, $P\left(^{*}\right)<0.05(\mathbf{I})$. Results are presented as mean + SD of three experiments, statistical significance was calculated using the Student's $T$-test with $P\left({ }^{*}\right)<0.05$ representing statistical significance between HIST1H1A and control vector group. 
Table 1: Summary of in vitro and in vivo studies using PC-3 and LNCaP cell lines over-expressing HIST1H1A

\begin{tabular}{lcc}
\hline In Vitro and In Vivo assays & PC-3 cells & LNCaP cells \\
\hline Soft agar assay & N/A & Increase \\
Growth assay & Decrease & Increase \\
Migration & Decrease & n.s Decrease \\
Invasion & Decrease & Decrease \\
Flank assay & Decrease & N/A \\
Intra-cardiac injections & Decrease & N/A \\
\hline
\end{tabular}

n.s represent non-significant.

Data represent results compared to cells expressing the control vector in each cell lines.

Table 2: Microarray data analysis of neuroendocrine gene transcripts dysregulated in LNCaP cells over-expressing HISTIH1A

\begin{tabular}{|c|c|c|c|c|c|}
\hline Transcript ID & Gene name & Gene symbol & RefSeq & $\begin{array}{c}P \text {-Value } \\
\text { (HIST1H1A vs. } \\
\text { Control) }\end{array}$ & $\begin{array}{c}\text { Fold-change } \\
\text { (HIST1H1A vs. } \\
\text { Control) }\end{array}$ \\
\hline 17104313 & Androgen receptor & $A R$ & NM_000044 & 0.00059 & -13.268 \\
\hline 16920548 & Aurora kinase $\mathrm{A}$ & AURKA & NM_003600 & 0.97544 & 1.00369 \\
\hline 16787650 & Chromogranin A & $C H G A$ & NM_001275 & 0.64767 & -1.05805 \\
\hline 16911201 & Chromogranin B & $C H G B$ & NM_001819 & 0.76382 & 1.03232 \\
\hline 16864616 & $\begin{array}{l}\text { Kallikrein-related } \\
\text { Peptidase } 3\end{array}$ & $K L K 3$ & NM_001030047 & 0.00069 & -12.0945 \\
\hline 16731297 & $\begin{array}{c}\text { Neural cell adhesion } \\
\text { Molecule } 1\end{array}$ & NCAM1 & NM_001076682 & 0.00129 & 2.43506 \\
\hline 17110835 & Synaptophysin & SYP & NM_003179 & 0.18923 & 1.1505 \\
\hline 16914315 & $\begin{array}{l}\text { Ubiquitin-conjugating } \\
\text { enzyme E2C }\end{array}$ & UBE2C & NM_001281741 & 0.20479 & 1.22344 \\
\hline
\end{tabular}

to the benign prostatic glands [30]. In addition, HIST1H1B reactivity was more positively associated with Gleason Score 4 and 5, pointing to the potential of this linker histone as a diagnostic tool [30].

Our study indicates for the first time that HIST1H1A expression is significantly suppressed in human prostate adenocarcinoma compared to its normal counterpart using prostate TMA. Whereby, in silico validation using the GSE21032 cohorts suggested that HIST1H1A expression was associated with Gleason Score, we found no significant association between Gleason Score and H1.1 TMA staining. However, the TMA data presented here was somewhat underpowered ( $n=80$ cases vs. $n=80$ controls), and a larger-scale analysis is required to address an association of H1.1 levels with tumor grade. Additionally, it would be of interest to determine whether H1.1 expression differs between prostate adenocarcinomas and NEPC. The latter will be the emphasis of future studies.

In our study, HIST1H1A over-expression in LNCaP cells significantly suppressed AR expression at the gene and protein level. In addition, opposing effects were observed with regards to the expression of a panel of NE marker genes in each of the cell lines. HIST1H1A expression enhances NE marker expression in LNCaP cells, yet suppressing their expression in PC-3 cells. These differences in the two cell lines induced by HIST1H1A over-expression may account for the differences in cell growth in LNCaP and PC-3 cells as well as tumor growth and metastasis in PC-3 cells, and supports a possible role for HIST1H1A in regulating AR signaling and EMT. The mechanisms through which HIST1H1A exert its effects in AR signaling and EMT are presently unclear, and is the focus of ongoing studies.

It was previously reported that activation of the WNT signaling pathway through $\beta$-catenin in LNCaP cells induced the expression of multiple NE markers [31]. In addition, histological studies of mouse prostate tissue following activation of WNT signaling through $\beta$-catenin showed evidence of elevated levels of chromogranin A, as well as the forkhead transcription factor, FOXA2, which are factors associated with neuroendocrine differentiation. Several studies have indicated that there is a correlation between loss of AR and NE differentiation [32-34]. In our study, both Western blot analysis and gene expression demonstrated that HIST1H1A over-expression in LNCaP cells lead to down-regulation of AR. In addition, pathway 
analysis identified $\mathrm{WNT} / \beta$-catenin signaling as the top canonical pathway associated with HIST1H1A overexpression. The WNT signaling pathway is involved in both embryogenesis and tumorigenesis [35]. In the prostatic epithelial tissue, WNT signaling regulates cell proliferation, differentiation, and maintenance through its interaction with $\beta$-catenin [36-38]. Mechanistically, the interaction between WNT signaling and AR signaling differs based on PC stage: WNT/ $\beta$-catenin signaling is associated with AR-target gene transcription in hormone naïve PC cells; however, in castrate-resistant PC, both $\mathrm{AR}$ and $\mathrm{WNT} / \beta$-catenin signaling stimulate each other resulting in activation of genes involved in PC cell growth in an androgen-independent manner [39]. In addition, WNT signaling was identified as the most androgen regulated pathway, during early prostate development [40]. In particular, introduction of AR mutation into the prostate epithelia of TRAMP mice resulted in enhanced tumor formation and growth as a consequence of stimulation of the non-canonical WNT signaling pathway, particularly through its ligand, WNT-5A [41].

In the presence of WNT signaling, phosphorylation of $\beta$-catenin is inhibited, allowing its translocation to the nucleus where it binds to transcription factors of the TCF/ LEF family and promote processes such as EMT [35]. EMT is a signaling pathway invoked during various stages of embryogenesis, including gastrulation, neural tube formation, as well as non-developmental processes such as wound healing. In addition, EMT is well documented in cancer progression and metastasis $[35,38,42]$. Cells that are locally invasive have been shown to lose their adherent characteristics through reduction of cell adhesion molecules such as E-Cadherin, and up-regulation of proteins such as Vimentin, and N-Cadherin. Several transcription factors such as Snail1 and Snail2 (Slug), Zeb1, Zeb2, and Twist1 have all been implicated in regulation of these cell adhesion

A

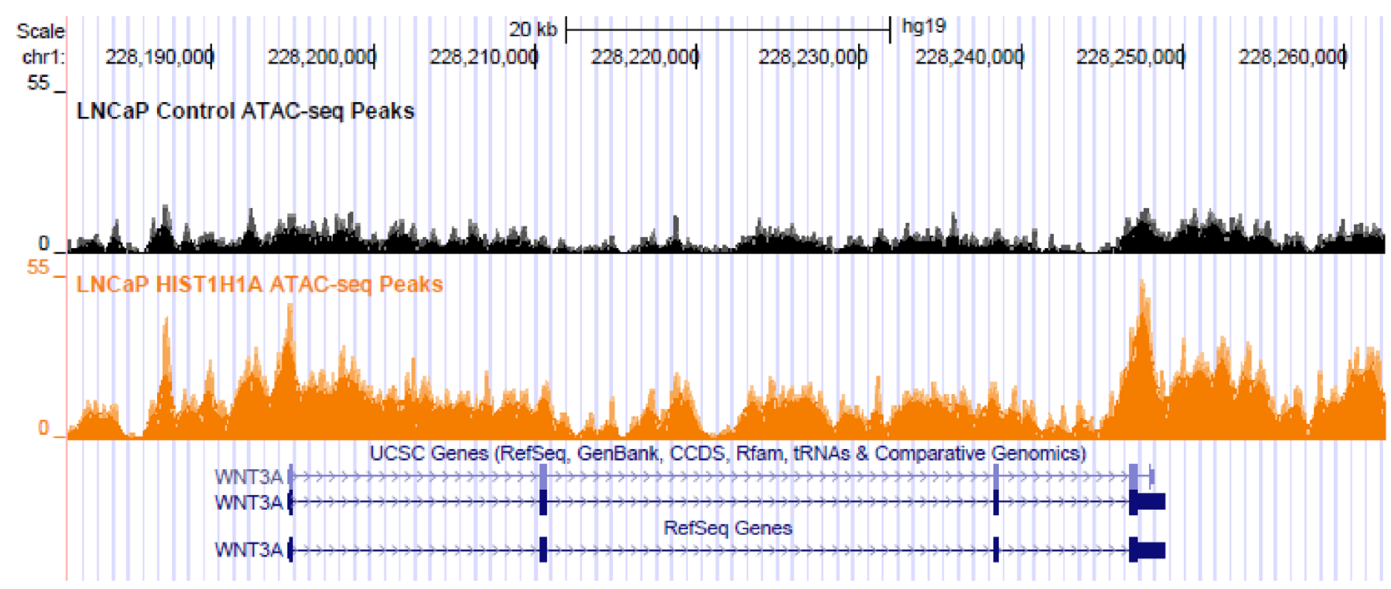

B

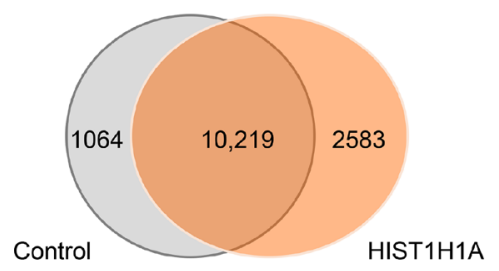

C

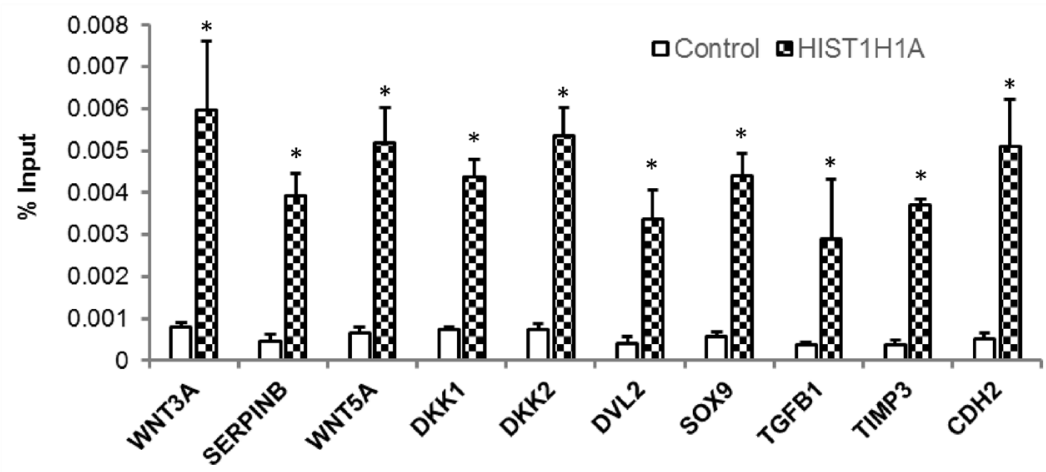

Figure 5: ATAC-seq analysis identified enhanced open chromatin regions in the presence of HIST1H1A. Tracks from UCSC genome browser following ATAC-sequencing was generated from LNCaP cells over-expressing either HISTIH1A or control vector. Analysis was done in triplicate and peak regions are representative of one sample; control peaks are shown in black and HIST1H1A peaks are shown in orange (A). Venn diagram showing overlap in genes found in open chromatin region following ATAC-seq analysis of LNCaP cells over-expressing HIST1H1A and control vector (B). Genes identified in the ATAC-seq analysis were validated using ChIP-qPCR in LNCaP cells over-expressing HIST1H1A or control vector. Graphs represent the average of three clonal isolates, presented as mean $+\mathrm{SD}$, $P\left({ }^{*}\right)<0.05(\mathbf{C})$. Statistical significance was calculated using the Student's $T$-test with $P\left({ }^{*}\right)<0.05$ representing statistical significance between HIST1H1A and control vector group. 
molecules [35, 38, 42, 43]. In the current study, we demonstrated that HISTIH1A modulates the expression of several of these genes involved in EMT.

In summary, this study suggests a plausible mechanism underlying the effect of HIST1H1A in aggressive human prostate tumorigenesis. As ADT treatment increases, it is expected that the proportion of patients suffering from the aggressive NEPC sub-type will also increase. Therefore, a clearer understanding of the mechanisms that underlie aggressive PC development will assist researchers in the development of better treatment options. Overall, we have provided evidence that systems genetics can be used to show how hereditary variation influences aggressive PC susceptibility.

\section{MATERIALS AND METHODS}

\section{Generation of stable cell line expressing HIST1H1A}

Human prostate tumor cell line LNCaP was obtained from American Type Culture Collection (ATCC), and grown in RPMI cell culture media. PC-3 Luc cell line was modified from PC-3 human prostate tumor cells to express luciferase and were donated from Dr. Kathleen Kelly at NCI/NIH [44]. PC-3 Luc cells were grown in DMEM cell culture media. Both LNCaP and PC-3 Luc cell growth media were supplemented with $10 \%$ FBS and $1 \%$ Penicillin/Streptomycin, and cell cultures were maintained at $37^{\circ} \mathrm{C}$ and $5 \% \mathrm{CO}_{2}$. HIST1H1A (GE Dharmacon, Lafayette, CO, USA, cat \# OHS6085-213573401) or a control vector were stably expressed in both cell lines using lentiviral transduction as previously described [45]. Following transduction, LNCaP cells harboring the vector of interest were selected using $3 \mu \mathrm{g} / \mathrm{mL}$ blasticidin, and PC-3 Luc cells were selected using $20 \mu \mathrm{g} / \mathrm{mL}$ blasticidin. Clonal isolates were obtained using serial dilution, and the expression of HIST1H1A was confirmed using Western blot and qRT-PCR.

\section{Cell proliferation and anchorage independent growth assays}

For cell proliferation assays, PC-3 Luc and LNCaP clonal isolates stably over-expressing HIST1H1A or control vector were seeded at $2.5 \times 10^{4}$ cells per well in 24 -well plates and allowed to adhere for 24 hours. For six consecutive days, duplicate wells containing cells were trypsinized and counted in a Cellometer slide counter to determine the growth rate. Anchorage independent growth was assessed using a soft agar colony formation assay, where $1 \times 10^{3}$ cells expressing either HIST1H1A or control vector were suspended in a $0.33 \%$ agar mixture, and seeded on top of a $0.5 \%$ nutrient-agar base in 24 -well plates. Each group of cells were plated in duplicate and allowed to grow at $37^{\circ} \mathrm{C}$ and $5 \% \mathrm{CO}_{2}$ for two weeks. Cell colonies were stained with $0.005 \%$ crystal violet and counted.

\section{Trans-well cell migration and invasion assay}

Cell migration and invasion assay were performed as previously described [16]. Briefly, PC-3 Luc or LNCaP cells stably over-expressing HIST1H1A or control vector were seeded at $5 \times 10^{5}$ cells in serum-free media into the upper chamber of 8.0 um 24-well cell inserts (ThermoFisher Scientific). For cell migration assays, membrane of inserts were coated with $5 \mu \mathrm{g}$ collagen I dissolved in $0.02 \mathrm{M}$ acetic acid. For invasion assays, insert membranes were coated with $30 \mu \mathrm{g}$ Matrigel (Corning) diluted in $0.01 \mathrm{M}$ Tris $(\mathrm{pH} 8.0$ ) and $0.7 \%$ $\mathrm{NaCl}$. Inserts were placed in 24-well tissue culture dishes containing $10 \%$ FBS in cell culture media, which serves as an attractant to the "serum starved" cells within the upper insert. 48 hours later, cells remaining in the upper chamber were gently removed using a cotton swab, and cells still attached to the lower surface (cells that have migrated or invaded across the membrane) were fixed with $4 \%$ paraformaldehyde, and stained with crystal violet $(0.05 \%$ in ethanol). Snapshots of migratory or invading cells were taken, and membranes with attached cells were destained in $300 \mu \mathrm{L}$ of $2 \%$ SDS. Absorbance was read in duplicates at $560 \mathrm{~nm}$ using a microplate reader (Molecular Devices, Sunnyvale, CA, USA). Statistical analyses were performed using Student's $T$-test and data are presented as mean \pm SD with $P<0.05$ considered as significant.

\section{RNA isolation and gene expression by quantitative real time PCR (qRT-PCR)}

Total RNA was extracted from clonal isolates of PC-3 or LNCaP cells expressing HIST1H1A or the control vector using RNeasy Plus Mini Kit (QIAGEN). The concentration and purity of isolated RNA was measured using a NanoDrop (Wilmington, DE USA). Total RNA was reversed transcribed using iScript DNA Synthesis Kit (Bio-Rad, Hercules, CA USA) according to the manufacturer's protocol. qRT-PCR were performed for gene expression using ABI Fast SYBR Green Master Mix (Life Technologies, Grand Island, NY USA) as previously described [45].

\section{Microarray analysis}

Total RNA from LNCaP clonal isolates expressing HIST1H1A or control vector were isolated using miRNeasy Mini Kit according to the manufacture's protocol (QIAGEN, Cat \#217004). Samples were processed using Affymetrix Human Gene 2.0 ST Array and GeneChip WT PLUS Reagent Kit (Santa Clara, CA USA) according to the manufacturer's protocol. Differential expression data was analyzed using Partek Genomic Suite, and heat maps 
were generated using R as previously described [45]. Omics data was analyzed using Ingenuity Pathway Analysis (IPA) (QIAGEN). For IPA the following parameters were used: All data sources Confidence $=$ experimentally observed; All Species = human; All tissue and primary cells using the stringent filter; Examined both interaction molecules and causal networks. All data from microarray analysis were submitted to Gene Omnibus GSE101982.

\section{Assay for transposase accessible chromatin (ATAC)-sequencing experiment and analysis}

Approximately $5 \times 10^{4}$ cells were taken from a combined pool of three independent clonal isolates of LNCaP cells stably over-expressing HIST1H1A or control vector. The cells were then lysed, and the transposition reaction was carried out using the Nextera DNA Sample Prep Kit (Illumina Cat \# FC-121-1032). Purification was performed using AmpureXP beads at room temperature. The transposed DNA fragments were amplified using PCR techniques as previously described (Cycles: $1-72^{\circ} \mathrm{C}$, 5 mins; 2-98 ${ }^{\circ} \mathrm{C}, 30$ secs; 3-98 ${ }^{\circ} \mathrm{C}, 10$ secs; 4-63 ${ }^{\circ} \mathrm{C}$, 30 secs; 5-72 ${ }^{\circ} \mathrm{C}, 1 \mathrm{~min}$; 6-Repeat steps 3-5, 4×; 7-Hold at $4^{\circ} \mathrm{C}$ ) [26]. ATAC-seq data was generated on the Illumina HiSeq2500 platform. Each sample was sequenced on four separate lanes, and single-end ATAC-seq data were obtained. ATAC-seq reads that passed the Illumina platform quality check were used for downstream analyses. ATACseq reads were mapped to the human hg19 reference genome sequence using the BWA aligner (BWA mem; v. 0.7.12). Unambiguously mapped reads were selected using samtools view with option -q 1. Mapping data for corresponding samples were merged using samtools merge, and bamToBed (v. 2.10.0) was used to generate BED files containing the mapped positions for the ATAC-seq data. ATAC-seq reads that mapped to genomic regions of low mappability (centromere, telomere, and satellite repeats) were removed. PCR duplicates were also removed by selecting only one read that mapped to a genomic position in the same orientation. ATAC-seq peak calling was performed with the MACS2 software (v. 2.1.1) using the callpeak command with the following options: - nomodel —shift 100 —extsize 200. Following ATAC-sequencing analysis, IPA analysis was performed. For IPA the following parameters were used: All data sources Confidence = experimentally observed; All Species = human; All tissue and primary cells using the stringent filter; Examined both interaction molecules and causal networks.

\section{Chromatin immunoprecipitation (ChIP) and validation using qRT-PCR}

ChIP-qPCR was used to validate target genes derived from the ATAC-seq analysis. Three independent clonal isolates from LNCaP cells stably over-expressing HIST1H1A or control vector were used for ChIP assays as previously described [45]. Briefly, 1\% formaldehyde was used to fixed cells, followed by cell lysis. Cell lysates were pre-cleared with Protein G Sepharose beads (GE Healthcare), then incubated with HIST1H1A (HPA043753, Sigma Life Science) or IgG (12-370, Millipore), and protein $\mathrm{G}$ Sepharose beads were added for overnight incubation at $4^{\circ} \mathrm{C}$. $\mathrm{NaCl}$ was used for reverse cross-linking, and DNA was extracted using Qiaquick PCR purification kit (Qiagen). The DNA product was used for ChIP-qPCR analysis, and samples were amplified in duplicates using ABI Fast SYBR Green Master Mix (Life Technologies, Grand Island, NY USA). Student's $T$-tests was used to calculate statistical significance, and data are presented as mean \pm SD with $P<0.05$ being considered significant.

\section{Western blot}

Protein expression in LNCaP and PC-3 cells was determined by Western blotting. Protein extraction was carried out using chromatin extraction buffer containing Complete Protease inhibitor cocktail (Roche, Germany). Protein concentration in the supernatant isolated from LNCaP cells was determined using a standard protocol of the Bradford assay. $30 \mu \mathrm{g}$ of protein from each sample was separated using SDS-polyacrylamide gel electrophoresis, then transferred onto PVDF transfer membrane (Millipore) using Trans-BLOT SD Semi-Dry Transfer Cell (BIO-RAD). The membrane was blocked for 1 hour using 5\% milk in TBS-T before incubation with the primary antibody (Sigma-Aldrich, St. Louis, MO, USA cat \# HPA043753) overnight at $4^{\circ} \mathrm{C}$, followed by incubation with secondary antibody (Millipore, Billerica, MA, USA) for $1 \mathrm{hr}$ at room temperature. Immunoblots were developed using enhanced chemiluminescence (Amersham Biosciences, Piscataway, NJ).

\section{Immunohistochemistry}

De-identified human prostate tissue microarray (TMA) samples were obtained from The Prostate Cancer Biorepository Network (PCBN). Frozen paraffin embedded tissue microarrays were dried for 1 hour at $60^{\circ} \mathrm{C}$. Deparaffinization, rehydration and epitope retrieval were done using Dako pre-treatment link platform using $50 \times$ citrate buffer $(\mathrm{pH}$ 6.1). HIST1H1A antibody (HPA043753, Sigma Life Science) was diluted 1:500 using Envision Flex Antibody Diluent (Dako). Automated IHC with Autostainer Link 48 (Dako) was performed using Envision Flex High-sensitivity visualization system (Dako) kit. Antibody incubation was programmed for $1 \mathrm{hr}$, and Envision FLEX Rabbit was used to amplify primary antibody signals. Samples were counterstained using EnVision FLEX Hematoxylin (Dako). Sample slides were dehydrated twice for two minutes each in the following solution $70 \%$ ethanol, $95 \%$ ethanol, $100 \%$ ethanol, and xylene, then cover slipped using Permaslip mounting 
media. Immunostaining of H1.1 in the tissue samples were categorized based on predominant staining intensity in the cells (negative $=0$, weak $=1$, moderate $=2$, and intense $=$ 3 ); and on the percentage of all positive cells, and weak to strong in the total cell population (negative $=0,1-5 \%=1$, $5-25 \%=2,25-50 \%=3$ and $50-100 \%=4)$. In the cancer cores, only invasive cancers were scored; in the epithelial component, only luminal epithelial cells were scored; and in the stromal components, only myofibroblasts, fibroblasts, and smooth muscle cells were scored. Wilcoxon rank sum test was used to determine statistical significance between prostate normal and adenocarcinoma group with $P<0.05$ representing significance.

\section{In vivo tumor xenograft and metastasis assay}

To monitor tumor growth that might be influenced by over-expression of HIST1H1A, $1 \times 10^{6}$ PC-3 Luc cells over-expressing $H I S T 1 H 1 A$ or control vector were re-suspended in $50 \mu \mathrm{L}$ phosphate buffered saline (PBS) and $50 \mu \mathrm{L}$ Matrigel (Corning, Bedford MA). Cells were injected subcutaneously into the flanks of 15 six-week old NU/J male mice (Jackson Laboratory, Bar Harbor $\mathrm{ME}$ ). Tumor growth was measured once a week for six weeks using a digital caliper. Volume of the tumors was calculated using the formula: Volume $=\left(\right.$ Width $^{2} \times$ Length) $/ 2$. The results are presented as mean $\pm \mathrm{SD}$.

The ability of cells to disseminate to distant sites in vivo was assessed using the intra-cardiac metastasis assay as previously described [17]. Briefly, 12 six-week old male $\mathrm{NU} / \mathrm{J}$ mice were injected with $1 \times 10^{5} \mathrm{PC}$-3-Luc cells overexpressing either HIST1H1A or control vector into the left cardiac ventricle. To monitor dissemination of tumor cells, mice were anesthetized with isoflurane, and injected with D-luciferin (150 mg/kg body weight). Bioluminescent images of tumors developing in the mice were acquired using the in vivo Xtreme Imager (Bruker, Billerica MA). The experiment was terminated when mice weight dropped by $10 \%$ of initial body weight or six weeks post-intracardiac injection. At termination of the experiment, necropsies were performed and mice exhibiting tumor growth in the chest cavity were excluded from data analysis due to cell spillage at the time of injection. Results are represented as mean $+\mathrm{SD}$. Both in vivo assays were performed at least twice. In the tumor xenograft experiment the Student's $T$-test was used to determine significance and for the metastasis experiment ANOVA was used to determine significance, with $P<0.05$ representing significance. All experiments utilizing mice were approved and performed in compliance with the National Human Genome Research Institute Animal Care and Use Committee's guidelines.

\section{Gene analysis in human expression datasets}

Logistic regression analysis was performed to determine the association between the expression levels of six hist1 gene transcripts identified in GWAS analysis with aggressive PC clinical variable, whereby the candidate gene expression level was presented as z-scores, as was previous described [17]. GSE21032 ( $N=150$ PC cases) and GSE46691 ( $N=545$ PC cases $)$ data sets consisting of microarray gene expression data, and the TCGA data set consisting of RNA-seq PC gene expression data was used to determine the z-scores by calculating the SD of the levels of transcript found in each case compared to the mean transcript expression in all tumors. TCGA and GSE21032 consists of tumor gene expression data obtained from cBioPortal for Cancer Genomics [46, 47], and GSE46691 consists of data obtained from Gene Expression Omnibus (https://www.ncbi.nlm.nih.gov/geo/ query/acc.cgi?acc=GSE46691). Benjamini-Hochberg FDR for univariate logistic regression $P$-value was performed to correct for multiple testing, where threshold for significance was set as FDR of 5\%. Kaplan-Meier survival analysis was performed using Medcalc, where survival time in all cohorts with higher or lower levels of tumor candidate gene expression was compared to all other cases. A z-score of $>2$ or $<-2$ denotes higher or lower levels of gene expression respectively.

\section{QTL mapping}

$\mathrm{J} / \mathrm{qtl}$ was used to map QTLs in our study as was previously described [15]. Briefly, QTLs were mapped for all traits using a single-QTL analysis, and using a binary model for binary trait, and a non-parametric model for all other traits. Permutation testing was used to test significance levels, using 10,000 permutations. QTL confidence intervals were estimated using 2-LOD support intervals, and QTLs reaching a genome-wide $\alpha<0.05$ were considered to be of interest.

\section{Abbreviations}

ADT: androgen deprivation therapy; AR: androgen receptor; ATAC: assay for transposase accessible chromatin; CI: confidence interval; ChIP: Chromatin Immunoprecipitation; Chr: Chromosome; DFS: diseasefree survival; EMT: epithelial to mesenchymal transition; FDR: false discovery rate; HA: hemagglutinin; IgG: immunoglobulin G; IHC, immunohistochemistry; IPA, Ingenuity Pathway Analysis; NE: neuroendocrine; NEPC: neuroendocrine prostate cancer; $\mathrm{OD}$ : odds ratio; PC: prostate cancer; PSA: prostate specific antigen; PVDF: polyvinylidene difluoride; QTL: quantitative trait locus; TBST: tris-buffered saline-Tween 20); TMA: tissue microarray.

\section{Author contributions}

Conceptualization, K.A.W., M.L., and N.P.S.C.; Data Analysis, K.A.W., M.L., J.M.W., D.E.G., C.C., H.Y., J.L., and N.P.S.C.; Experimental Procedure, K.A.W., M.L., 
J.M.W., N.L.C., C.C.; Writing Original Draft, K.A.W., and N.P.S.C.; Review and Editing, K.A.W., M.L., J.M.W., N.L.C., D.E.G., C.C., H.Y., J.L., and N.P.S.C.

\section{ACKNOWLEDGMENTS AND FUNDING}

This research was supported by the Intramural Research Program of the National Human Genome Research Institute, National Institutes of Health (HG200366-05); and the Department of Defense Prostate Cancer Research Program, Award No W81XWH14-2-0182, W81XWH-14-2-0183, W81XWH-14-2-0185, W81XWH-14-2-0186, and W81XWH-15-2-0062 Prostate Cancer Biorepository Network (PCBN).

\section{CONFLICTS OF INTEREST}

The authors declare no conflicts of interest.

\section{REFERENCES}

1. Siegel RL, Miller KD, Jemal A. Cancer statistics, 2018. CA Cancer J Clin. 2018; 68:7-30. https:// doi.org/10.3322/caac.21442.

2. Chang AJ, Autio KA, Roach M 3rd, Scher HI. High-risk prostate cancer-classification and therapy. Nat Rev Clin Oncol. 2014; 11:308-23. https://doi.org/10.1038/nrclinonc.2014.68.

3. Rodrigues DN, Boysen G, Sumanasuriya S, Seed G, Marzo AM, de Bono J. The molecular underpinnings of prostate cancer: impacts on management and pathology practice. J Pathol. 2017; 241:173-82. https://doi.org/10.1002/path.4826.

4. Klotz L, Emberton M. Management of low risk prostate canceractive surveillance and focal therapy. Nat Rev Clin Oncol. 2014; 11:324-34. https://doi.org/10.1038/nrclinonc.2014.73.

5. Ryan CJ, Smith MR, de Bono JS, Molina A, Logothetis CJ, de Souza P, Fizazi K, Mainwaring P, Piulats JM, Ng S, Carles J, Mulders PF, Basch E, et al, and COU-AA-302 Investigators. Abiraterone in metastatic prostate cancer without previous chemotherapy. N Engl J Med. 2013; 368:138-48. https://doi.org/10.1056/NEJMoa1209096.

6. Scher HI, Fizazi K, Saad F, Taplin ME, Sternberg CN, Mi ller K, de Wit R, Mulders P, Chi KN, Shore ND, Armstrong AJ, Flaig TW, Fléchon A, et al, and AFFIRM Investigators. Increased survival with enzalutamide in prostate cancer after chemotherapy. N Engl J Med. 2012; 367:1187-97. https://doi.org/10.1056/NEJMoa1207506.

7. O'Donnell A, Judson I, Dowsett M, Raynaud F, Dearnaley D, Mason M, Harland S, Robbins A, Halbert G, Nutley B, Jarman M. Hormonal impact of the 17alphahydroxylase/ $C(17,20)$-lyase inhibitor abiraterone acetate (CB7630) in patients with prostate cancer. Br J Cancer. 2004; 90:2317-25. https://doi.org/10.1038/sj.bjc.6601879.

8. Attard G, Reid AH, Yap TA, Raynaud F, Dowsett M, Settatree S, Barrett M, Parker C, Martins V, Folkerd E, Clark J, Cooper CS, Kaye SB, et al. Phase I clinical trial of a selective inhibitor of CYP17, abiraterone acetate, confirms that castration-resistant prostate cancer commonly remains hormone driven. J Clin Oncol. 2008; 26:4563-71. https://doi.org/10.1200/JCO.2007.15.9749.

9. Tran C, Ouk S, Clegg NJ, Chen Y, Watson PA, Arora V, Wongvipat J, Smith-Jones PM, Yoo D, Kwon A, Wasielewska T, Welsbie D, Chen CD, et al. Development of a second-generation antiandrogen for treatment of advanced prostate cancer. Science. 2009; 324:787-90. https:// doi.org/10.1126/science. 1168175 .

10. Boudadi K, Antonarakis ES. Resistance to Novel Antiandrogen Therapies in Metastatic Castration-Resistant Prostate Cancer. Clin Med Insights Oncol. 2016; 10:1-9. https://doi.org/10.4137/CMO.S34534.

11. Grigore AD, Ben-Jacob E, Farach-Carson MC. Prostate cancer and neuroendocrine differentiation: more neuronal, less endocrine? Front Oncol. 2015; 5:37. https://doi.org/10.3389/fonc.2015.00037.

12. Jiborn T, Bjartell A, Abrahamsson PA. Neuroendocrine differentiation in prostatic carcinoma during hormonal treatment. Urology. 1998; 51:585-9.

13. Shah RB, Mehra R, Chinnaiyan AM, Shen R, Ghosh D, Zhou M, Macvicar GR, Varambally S, Harwood J, Bismar TA, Kim R, Rubin MA, Pienta KJ. Androgen-independent prostate cancer is a heterogeneous group of diseases: lessons from a rapid autopsy program. Cancer Res. 2004; 64:9209-16. https:// doi.org/10.1158/0008-5472.CAN-04-2442.

14. Terry S, Beltran H. The many faces of neuroendocrine differentiation in prostate cancer progression. Front Oncol. 2014; 4:60. https://doi.org/10.3389/fonc.2014.00060.

15. Williams KA, Lee M, Hu Y, Andreas J, Patel SJ, Zhang S, Chines P, Elkahloun A, Chandrasekharappa S, Gutkind JS, Molinolo AA, Crawford NP. A systems genetics approach identifies CXCL14, ITGAX, and LPCAT2 as novel aggressive prostate cancer susceptibility genes. PLoS Genet. 2014; 10:e1004809. https://doi.org/10.1371/journal.pgen.1004809.

16. Lee M, Williams KA, Hu Y, Andreas J, Patel SJ, Zhang S, Crawford NP. GNL3 and SKA3 are novel prostate cancer metastasis susceptibility genes. Clin Exp Metastasis. 2015; 32:769-82. https://doi.org/10.1007/s10585-015-9745-y.

17. Winter JM, Gildea DE, Andreas JP, Gatti DM, Williams KA, Lee M, Hu Y, Zhang S, Program NCS, Mullikin JC, Wolfsberg TG, McDonnell SK, Fogarty ZC, et al. Mapping Complex Traits in a Diversity Outbred F1 Mouse Population Identifies Germline Modifiers of Metastasis in Human Prostate Cancer. Cell Syst. 2017; 4:31-45 e6. https://doi.org/10.1016/j.cels.2016.10.018.

18. Happel N, Doenecke D. Histone H1 and its isoforms: contribution to chromatin structure and function. Gene. 2009; 431:1-12. https://doi.org/10.1016/j.gene.2008.11.003.

19. Sancho M, Diani E, Beato M, Jordan A. Depletion of human histone $\mathrm{H} 1$ variants uncovers specific roles in gene expression and cell growth. PLoS Genet. 2008; 4:e1000227. https://doi.org/10.1371/journal.pgen.1000227. 
20. Izzo A, Kamieniarz-Gdula K, Ramirez F, Noureen N, Kind J, Manke T, van Steensel B, Schneider R. The genomic landscape of the somatic linker histone subtypes H1.1 to H1.5 in human cells. Cell Reports. 2013; 3:2142-54. https://doi.org/10.1016/j.celrep.2013.05.003.

21. Franke K, Drabent B, Doenecke D. Expression of murine H1 histone genes during postnatal development. Biochim Biophys Acta. 1998; 1398:232-42.

22. Tai S, Sun Y, Squires JM, Zhang H, Oh WK, Liang CZ, Huang J. PC3 is a cell line characteristic of prostatic small cell carcinoma. Prostate. 2011; 71:1668-79. https://doi.org/10.1002/pros.21383.

23. Schaid DJ, McDonnell SK, Zarfas KE, Cunningham JM, Hebbring S, Thibodeau SN, Eeles RA, Easton DF, Foulkes WD, Simard J, Giles GG, Hopper JL, Mahle L, et al. Pooled genome linkage scan of aggressive prostate cancer: results from the International Consortium for Prostate Cancer Genetics. Hum Genet. 2006; 120:471-85. https://doi.org/10.1007/s00439-006-0219-9.

24. Taylor BS, Schultz N, Hieronymus H, Gopalan A, Xiao Y, Carver BS, Arora VK, Kaushik P, Cerami E, Reva B, Antipin Y, Mitsiades N, Landers $\mathrm{T}$, et al. Integrative genomic profiling of human prostate cancer. Cancer Cell. 2010; 18:11-22. https://doi.org/10.1016/j.ccr.2010.05.026.

25. Erho N, Crisan A, Vergara IA, Mitra AP, Ghadessi M, Buerki C, Bergstralh EJ, Kollmeyer T, Fink S, Haddad Z, Zimmermann B, Sierocinski T, Ballman KV, et al. Discovery and validation of a prostate cancer genomic classifier that predicts early metastasis following radical prostatectomy. PLoS One. 2013; 8:e66855. https://doi.org/10.1371/journal.pone.0066855.

26. Buenrostro JD, Wu B, Chang HY, Greenleaf WJ. ATAC-seq: A Method for Assaying Chromatin Accessibility GenomeWide. Curr Protoc Mol Biol. 2015; 109:21 9 1-9. https:// doi.org/10.1002/0471142727.mb2129s109.

27. Rabini S, Franke K, Saftig P, Bode C, Doenecke D, Drabent B. Spermatogenesis in mice is not affected by histone H1.1 deficiency. Exp Cell Res. 2000; 255:114-24. https:// doi.org/10.1006/excr.1999.4767.

28. Medrzycki M, Zhang Y, McDonald JF, Fan Y. Profiling of linker histone variants in ovarian cancer. Front Biosci. 2012; 17:396-406.

29. Hechtman JF, Beasley MB, Kinoshita Y, Ko HM, Hao K, Burstein DE. Promyelocytic leukemia zinc finger and histone H1.5 differentially stain low- and high-grade pulmonary neuroendocrine tumors: a pilot immunohistochemical study. Hum Pathol. 2013; 44:1400-5. https://doi.org/10.1016/j.humpath.2012.11.014.

30. Khachaturov V, Xiao GQ, Kinoshita Y, Unger PD, Burstein DE. Histone H1.5, a novel prostatic cancer marker: an immunohistochemical study. Hum Pathol. 2014; 45:2115-9. https://doi.org/10.1016/j.humpath.2014.06.015.

31. Yang X, Chen MW, Terry S, Vacherot F, Chopin DK, Bemis DL, Kitajewski J, Benson MC, Guo Y, Buttyan R. A human- and male-specific protocadherin that acts through the wnt signaling pathway to induce neuroendocrine transdifferentiation of prostate cancer cells. Cancer Res. 2005; 65:5263-71. https:// doi.org/10.1158/0008-5472.CAN-05-0162.

32. Yu X, Wang Y, DeGraff DJ, Wills ML, Matusik RJ. Wnt/ beta-catenin activation promotes prostate tumor progression in a mouse model. Oncogene. 2011; 30:1868-79. https:// doi.org/10.1038/onc.2010.560.

33. Sciarra A, Mariotti G, Gentile V, Voria G, Pastore A, Monti S, Di Silverio F. Neuroendocrine differentiation in human prostate tissue: is it detectable and treatable? BJU Int. 2003; 91:438-45.

34. Huss WJ, Gray DR, Tavakoli K, Marmillion ME, Durham LE, Johnson MA, Greenberg NM, Smith GJ. Origin of androgen-insensitive poorly differentiated tumors in the transgenic adenocarcinoma of mouse prostate model. Neoplasia. 2007; 9:938-50.

35. Gonzalez DM, Medici D. Signaling mechanisms of the epithelial-mesenchymal transition. Sci Signal. 2014; 7:re8. https://doi.org/10.1126/scisignal.2005189.

36. Wang BE, Wang XD, Ernst JA, Polakis P, Gao WQ. Regulation of epithelial branching morphogenesis and cancer cell growth of the prostate by Wnt signaling. PLoS One. 2008; 3:e2186. https://doi.org/10.1371/journal.pone.0002186.

37. Prins GS, Putz O. Molecular signaling pathways that regulate prostate gland development. Differentiation. 2008; 76:641-59. https://doi.org/10.1111/j.1432-0436.2008.00277.x.

38. Zhang J, Tian XJ, Xing J. Signal Transduction Pathways of EMT Induced by TGF-beta, SHH, and WNT and Their Crosstalks. J Clin Med. 2016; 5:E41. https:// doi.org/10.3390/jcm5040041.

39. Pakula H, Xiang D, Li Z. A Tale of Two Signals: AR and WNT in Development and Tumorigenesis of Prostate and Mammary Gland. Cancers (Basel). 2017; 9:E14. https:// doi.org/10.3390/cancers9020014.

40. Schaeffer EM, Marchionni L, Huang Z, Simons B, Blackman A, Yu W, Parmigiani G, Berman DM. Androgen-induced programs for prostate epithelial growth and invasion arise in embryogenesis and are reactivated in cancer. Oncogene. 2008; 27:7180-91. https://doi.org/10.1038/onc.2008.327.

41. Takahashi S, Watanabe $\mathrm{T}$, Okada $\mathrm{M}$, Inoue $\mathrm{K}$, Ueda $\mathrm{T}$, Takada I, Watabe T, Yamamoto Y, Fukuda T, Nakamura T, Akimoto C, Fujimura T, Hoshino M, et al. Noncanonical Wnt signaling mediates androgen-dependent tumor growth in a mouse model of prostate cancer. Proc Natl Acad Sci U S A. 2011; 108:4938-43. https://doi.org/10.1073/pnas.1014850108.

42. Tania M, Khan MA, Fu J. Epithelial to mesenchymal transition inducing transcription factors and metastatic cancer. Tumour Biol. 2014; 35:7335-42. https:// doi.org/10.1007/s13277-014-2163-y.

43. Lindsey S, Langhans SA. Crosstalk of Oncogenic Signaling Pathways during Epithelial-Mesenchymal Transition. Front Oncol. 2014; 4:358. https://doi.org/10.3389/fonc.2014.00358. 
44. Yin J, Pollock C, Tracy K, Chock M, Martin P, Oberst M, Kelly K. Activation of the RalGEF/Ral pathway promotes prostate cancer metastasis to bone. Mol Cell Biol. 2007; 27:7538-50. https://doi.org/10.1128/MCB.00955-07.

45. Lee M, Dworkin AM, Lichtenberg J, Patel SJ, Trivedi NS, Gildea D, Bodine DM, Crawford NP. Metastasis-associated protein ribosomal RNA processing 1 homolog B (RRP1B) modulates metastasis through regulation of histone methylation. Mol Cancer Res. 2014; 12:1818-28. https:// doi.org/10.1158/1541-7786.MCR-14-0167.

46. Cerami E, Gao J, Dogrusoz U, Gross BE, Sumer SO, Aksoy BA, Jacobsen A, Byrne CJ, Heuer ML, Larsson E,
Antipin Y, Reva B, Goldberg AP, et al. The cBio cancer genomics portal: an open platform for exploring multidimensional cancer genomics data. Cancer Discov. 2012; 2:401-4. https://doi.org/10.1158/2159-8290.CD-12-0095.

47. Gao J, Aksoy BA, Dogrusoz U, Dresdner G, Gross B, Sumer SO, Sun Y, Jacobsen A, Sinha R, Larsson E, Cerami E, Sander C, Schultz N. Integrative analysis of complex cancer genomics and clinical profiles using the cBioPortal. Sci Signal. 2013; 6:pl1. https://doi.org/10.1126/scisignal.2004088. 